\title{
Changes in smoking during retirement transition: A longitudinal cohort study
}

Anna Pulakka ${ }^{1}$, Jaana I. Halonen ${ }^{2}$, Jaana Pentti ${ }^{1,3}$, Mika Kivimäki ${ }^{2,3,4}$, Jussi Vahtera ${ }^{1 *}$, Sari Stenholm ${ }^{1 *}$

1 Department of Public Health, University of Turku and Turku University Hospital, Turku, Finland 2 Finnish Institute of Occupational Health, Helsinki/Kuopio, Finland

3 Department of Public Health, Faculty of Medicine, University of Helsinki, Helsinki, Finland 4 University College London Medical School, United Kingdom

*Shared senior authors

Corresponding author: Anna Pulakka, PhD, Department of Public Health, University of Turku and Turku University Hospital, Joukahaisenkatu 3-5, FI-20014 Turku, Finland. E-mail: anna.pulakka@utu.fi, Tel. +358 445749920

Key words: Ageing, smoking, cohort, retirement, trajectory 


\begin{abstract}
Aims: We examined the effect of retirement transition on changes in smoking, identified trajectories of smoking around the retirement transition, and investigated factors predicting the membership in the trajectories.
\end{abstract}

Methods: This longitudinal cohort study included 1,432 current or former smokers who entered into statutory retirement in 2000-2011 and who filled out 2-4 questionnaires sent by 4-year intervals. Effect of retirement on smoking was analysed as a non-randomised pseudo-trial in which we compared the likelihood of quitting and relapsing smoking between two subsequent survey waves among those who retired and did not retire. We used latent class analysis to identify trajectories of smoking status and smoking intensity (low: $<10$ cigarettes/day or high: $\geq 10$ cigarettes/day), and multinomial logistic regression models to assess pre-retirement factors associating with smoking trajectories.

Results: Retirement transition was associated with 1.7-fold odds of quitting smoking (95\% confidence intervals 1.3-2.2) compared to no such transition. We identified three smoking status trajectories: "sustained non-smoking" (61\% of the participants), "sustained smoking" (23\%), and “decreasing smoking" (16\%). For 489 baseline smokers we identified three smoking intensity trajectories: "sustained high intensity smoking" (32\% of the participants), "sustained low intensity smoking" (32\%), and "decreasing high intensity smoking" (35\%). Living outside inner urban area predicted membership in the "decreasing smoking" versus "sustained smoking" trajectory.

Conclusion: Smokers are more likely to quit smoking during transition to retirement than before or after it. Characteristics of the smoking environment may affect smoking behaviour around retirement. 


\section{Background}

Transition to retirement is a major life event resulting in changes e.g. in time availability, daily routines, social networks and income [1]. Previous longitudinal studies have reported changes in health behaviours, such as physical activity [2] and alcohol consumption [3] around retirement transition. Another behaviour that may change around retirement is tobacco smoking [4-6].

Retirement often results in reduced income, which may limit the ability to buy cigarettes. Retirement transition has also been identified as a period for positive changes in other health behaviours $[2,7]$. Conversely, transition to retirement can make smoking easier by removing the constraints for smoking place or time posed by work, e.g. smoking bans in workplaces. Moreover, retirement transition challenges a person to deal with loss of work role and societal ties of work [8] and may therefore decrease subjective well-being [1,9] and increase stress, which may affect smoking.

The association between retirement transition and smoking remains inconclusive. In a crosssectional study, a higher prevalence of smoking was found among retirees than non-retirees [10]. Previous longitudinal studies have generally relied only on one measurement before and one after retirement [4]. A few studies have monitored smoking behaviours repeatedly throughout retirement transition [5,11-13]. One study found no significant short- or long-term effects of retirement on smoking status [11]. In three studies, prevalence of smoking decreased quite steadily throughout the retirement transition $[5,12,13]$, with the decrease accelerating before retirement for women [5] and after retirement for men [5,13]. 
Only few studies have examined changes in smoking intensity during retirement transition $[10,11,14]$. These studies have again concluded with contrasting results with retirement either increasing [10] or decreasing $[11,14]$ the number of cigarettes smoked. Smoking intensity is of interest because it can capture more subtle changes in smoking behaviour than examining changes in smoking cessation only. However, the extent to which the decrease in smoking is attributable to retirement or aging remains open in all studies.

Given the heterogeneity in earlier findings, multiple subgroups with different trajectories of smoking behaviour around retirement transition are plausible. These subgroups might be defined by different, currently poorly understood, individual-level factors. In this study, we seek to address some of the research gaps by using repeated measurements of individual-level data on tobacco smoking and smoking intensity before and after transitioning to statutory retirement. The aim of this study was to (1) examine the effect of transition to statutory retirement on quitting smoking and smoking relapse, (2) identify trajectories of smoking status and smoking intensity during transition to statutory retirement, and (3) assess pre-retirement factors of belonging to each trajectory.

\section{Methods}

\section{Study population and setting}

The data were from the Finnish Public Sector (FPS) study, an ongoing prospective cohort study $[2,3]$ that consists of public sector employees from ten towns and six hospital districts who received identifiable questionnaires at 4-year intervals. We used data from surveys of current employees in 2000-2002, 2004 and 2008, and surveys of those who had left the organizations in 2005, 2009 and 2013 (Supplemental Figure S1). The FPS study was approved by the Ethics Committee of the Hospital District of Helsinki and Uusimaa. Among the cohort members, we first identified persons 
who were employed and responded to at least one survey in 2000-2002, 2004 or 2008 (n=81,587, Supplemental Figure S2). Of these, 9,433 were awarded statutory pension as their first pension by December 31, 2011, and of these, 5,898 persons had responded to at least one survey also after retirement. We focused on statutory retirement, because other types of retirement (e.g. disability retirement) are likely associated with diseases and other conditions that may influence smoking behaviour.

We centred the data on the retirement date. There were three possible study waves before $\left(\mathrm{W}_{-3}, \mathrm{~W}_{-2}\right.$, $\left.\mathrm{W}_{-1}\right)$, and three after $\left(\mathrm{w}_{+1}, \mathrm{~W}_{+2}, \mathrm{w}_{+3}\right)$ retirement. We only included ever-smokers who had participated in at least the last survey before and the first survey after transition to statutory retirement (i.e., $\mathrm{w}_{-1}$ and $\mathrm{w}_{+1}$ ), and who stated being current or former smoker at the last survey before retirement $\left(\mathrm{w}_{-1}\right), \mathrm{N}=1,432$. For the smoking intensity analyses, we further limited the sample to current smokers in survey $\mathrm{w}_{-1}$ who gave information on smoking intensity in surveys $\mathrm{w}_{-1}$ and $\mathrm{w}_{+1}$, $\mathrm{N}=489$. Never-smokers were not included in the analyses because starting smoking is very uncommon in this age group: only $0.7 \%$ of those reporting never-smoking at $\mathrm{w}_{-1}$ reported being a smoker in any of the subsequent surveys.

\section{Assessment of retirement}

We obtained data on the retirement type and date of each participant between 2000 and 2011 from the Finnish Centre for Pensions, which coordinates all the earnings-related pensions for permanent residents in Finland.

\section{Assessment of smoking}

Smoking status was assessed identically at each study wave. The first questions was: "Do you smoke or have you previously smoked regularly, that is daily or nearly daily?", followed by: "Do 
you still smoke regularly?". Participants who responded "yes" to both of the questions were defined as current smokers, while those who responded "yes" to the first question and "no" to the latter question were defined as former smokers in the study wave in concern.

Smoking intensity was assessed by asking: "How many cigarettes do you on average smoke daily?". The response options were: "none”, "less than 5", “5-9”, “10-14”, "15-19”, “20-24”, “2539", and "over 40". We categorized the smoking intensity as low ( $<10$ cigarettes/day) or high $(\geq 10$ cigarettes/day) [15]. In the smoking intensity analysis, the number of smoked cigarettes was set to zero for quitters.

\section{Assessment of covariates}

Data on covariates came from the last survey before retirement $\left(\mathrm{W}_{-1}\right)$. We obtained sex, date of birth, age at retirement, and occupational title from the employers' registers. We categorized occupational status according to the International Classification of Occupations [16] as high, intermediate, and low. Level of education was obtained from Statistics Finland [17] and classified as high (university degree), intermediate (high school or vocational school), and low (basic education).

Information on marital status and lifestyle-related factors were obtained from the surveys. Marital status was categorized as single, divorced/widowed, and married/cohabiting. We defined heavy alcohol consumption as >16 units/week for women and >24 units/week for men, one unit corresponding to $12 \mathrm{~g}$ of pure alcohol, or passing out at least once due to heavy drinking during the past 12 months [18]. Level of physical activity was measured as weekly Metabolic Equivalent Task (MET) hours [19] and categorized into low ( $<14$ MET hours/week) or moderate-to-high $(\geq 14$ MET hours/week) [20]. We calculated body mass index (BMI) based on self-reported weight and height 
$\left(\mathrm{kg} / \mathrm{m}^{2}\right)$ and categorized the respondents as normal weight $\left(\mathrm{BMI}<25.0 \mathrm{~kg} / \mathrm{m}^{2}\right.$ ) or overweight/obese $\left(\mathrm{BMI} \geq 25 \mathrm{~kg} / \mathrm{m}^{2}\right)$ [21]. Individuals who were underweight $(\mathrm{n}=5)$ were included in the normal weight category.

We used questions from the Job Content Questionnaire and Demand-Control Questionnaire [22] to define job strain as having high demands ( $>$ median demand score) and low control $(<$ median control score for the whole cohort) and assigned other combinations of job demands and control to the no strain-category [23]. Self-reported health was determined by the question: "How is your health?" and categorized as "poor" (poor, fairly poor or average) or "good” (good or fairly good). Information on depression was based on the Finnish Prescription Register kept by the Social Insurance Institution of Finland (SII) (ATC code N06A). Disease status was obtained from nationwide registers: coronary heart disease, asthma, and diabetes based on Drug Reimbursement Register by SII, and cancer from the Finnish Cancer Registry. Participants were categorized as having no disease, or one or more diseases before retirement, taking into account chronic diseases in all the pre-retirement waves available.

Data for adult neighbourhood disadvantage were obtained from the Statistics Finland's grid database for the year 2008, which contains information for all Finnish residents on social and economic characteristics shown at the level of $250 \times 250 \mathrm{~m}$ grids (i.e. neighbourhood) [24]. We used information on income (coded inversely), unemployment rates, and the proportion of those with a low level of education as the determinants of neighbourhood disadvantage, and operationalized them as in the previous studies [25]. We linked these data to the participants' home addresses at the time of w-1 using the latitude and longitude coordinates. Participants' residential neighbourhood was also categorised according to the Finnish Environment 
Institute's urban-rural classification as inner urban area (compact and densely built area with continuous development), or other [26].

\section{Statistical analyses}

First, we examined the effect of retirement transition on quitting smoking and smoking relapse by applying a design where longitudinal observational data are treated as a sequence of nonrandomised pseudo-trials that mimics the selection process of clinical trials $[27,28]$. To examine quitting smoking, we included all pairs of two consecutive surveys where the participant was a current smoker at the first wave. The pair of surveys where the participant retired in between the surveys served as a "treatment" group, while all pairs of surveys where the participant was either a non-retiree or a retiree at both of the survey waves served as a "control" group (See Supplemental Figure S1 for illustration). We compared the likelihood of quitting smoking between the "treatment" and the "control" groups. In a corresponding way, to examine smoking relapse, we included all pairs of two consecutive surveys where the participant was a former smoker at the first wave, and compared the likelihood of starting smoking between the "treatment" and the "control" groups. The results are reported as odds ratios and their 95\% confidence intervals (CI) derived from generalised estimating equation (GEE) models (PROC GENMOD in SAS). GEE models account for within-person correlation from those participants who contributed to more than one paired observations.

Second, we identified trajectories of 1) smoking status (based on the repeated question of smoking status) and 2) smoking intensity (based on the repeated question of smoking intensity) throughout retirement transition using latent class analysis (LCA). LCA is a statistical method used for identifying mutually exclusive latent classes, or trajectories, of individuals with similar response profiles and it has been used to identify latent classes in longitudinal data based on one question 
presented repeatedly in successive study waves $[3,29,30]$. We examined one to five class solutions and selected the model with the best fit based on Akaike's Information Criterion and Bayesian Information Criterion values (model with smaller values indicate a better fit) for the analyses.

Third, we used multinomial logistic regression models to assess which pre-retirement factors predicted membership of each smoking trajectory. The pre-retirement predictors, measured at $\mathrm{w}_{-1}$, included sex, age at retirement, marital status, occupational status, education, self-rated health, presence of chronic diseases, depression, heavy alcohol consumption, physical activity, BMI, neighbourhood disadvantage, urban area, and job strain. All models were adjusted for sex and, to control for changes in the patterns of smoking and tobacco control policies over time, year of birth. Statistical analyses were performed with SAS 9.4 Statistical Package (SAS Institute Inc., Cary, NC). 


\section{Results}

\section{Selection and background information}

The baseline characteristics of the 1,432 ever smokers and 489 current smokers are presented in Table 1. Of the participants included in the smoking status analyses, $68 \%, 25 \%$ and $8 \%$ provided information at four, three and two study waves, respectively, while the corresponding figures for smoking intensity analysis were $63 \%, 26 \%$ and $10 \%$. The 5,898 respondents were only slightly different compared to the eligible population of 7,466 people in terms of sex ( $80 \%$ vs. $79 \%$ female), occupational status $(35 \%, 27 \%$, and $38 \%$ vs. $37 \%, 26 \%$, and $37 \%$ with low, intermediate, and high status, respectively) and education $(15 \%, 29 \%$, and $56 \%$ vs. $17 \%, 30 \%$, and $53 \%$ with low, intermediate, and high, respectively).

\section{Pseudo-trial for quitting smoking and smoking relapse}

In the pseudo-trial on quitting smoking, there were 497 participants in the "treatment" group (i.e. retirement transition) and 465 in the control group (i.e. no retirement transition). Compared to the “control" group, retirement transition was associated with a higher likelihood to quit smoking (OR $1.65,95 \%$ CI 1.26 to 2.17 , Table 2). Regarding smoking relapse, based on paired observations from the 935 participants in the "treatment" group and 914 in the "control group", there was no difference between the groups (OR $1.08,95 \%$ CI 0.70 to 1.67 ).

\section{Latent classes for smoking status}

A three-class LCA model showed the best fit for smoking status analysis (Supplementary Table S1). The three trajectories were named as "sustained non-smoking", "sustained smoking", and “decreasing smoking” (Figure 1, panel A). The majority of the participants (61\%) were in the 
"sustained non-smoking", followed by the "sustained smoking" (23\%) and the "decreasing smoking" (16\%) trajectories.

Pre-retirement predictors for belonging to the different trajectories are presented in Table 3. Compared to the "sustained smoking", members in the "sustained non-smoking" group had more often higher occupational and educational statuses, and lived in socioeconomically advantaged areas and outside inner urban areas. Moderate-to-high physical activity and overweight were more common among the latter group. Only one pre-retirement factor differentiated the "decreasing smoking" trajectory from the "sustained smoking" trajectory: those in the "decreasing smoking" trajectory were more likely to live outside inner urban area (OR 1.78, 95\% CI 1.14 to 2.76).

\section{Latent classes for smoking intensity}

A three-class LCA model showed the best fit for smoking intensity (Supplementary Table S1), with fairly equal number of participants in each trajectory: $32 \%$ in the "sustained high intensity smoking", $32 \%$ in the "sustained low intensity smoking", and $36 \%$ in the "decreasing high intensity smoking” trajectory (Figure 1, panel B).

Table 4 presents the predictors for belonging to the smoking intensity trajectories. Those in the "sustained low intensity smoking" trajectory were more likely female, retiring at older age, physically active, lived in socioeconomically advantaged neighbourhoods, and had good self-rated health and normal weight compared to those in the "sustained high intensity smoking" trajectory. We found no factors predicting membership of the "decreasing high intensity smoking" trajectory when compared with the "sustained high intensity smoking". 


\section{Discussion}

In this large longitudinal cohort study on current and former smokers who entered into statutory retirement, the transition phase to retirement was associated with $65 \%$ higher odds for quitting smoking compared to times before and after retirement transition. Three trajectories of smoking were found: former smokers who remained non-smokers following retirement transition (61\%), smokers who continued smoking (23\%) and smokers who quit smoking (16\%) during this transition. In terms of smoking intensity, $32 \%$ of the participants who smoked immediately before retirement sustained high intensity smoking, 32\% sustained low intensity smoking, and 36\% decreased their smoking intensity.

Compared to most of the previous studies, the major strengths of this large study were long followup with repeated measurements both before and after retirement, and use of a pseudo-trial design which enabled us to separate the effect of retirement from the age-related changes in smoking. In addition, LCA allowed us to find underlying subgroups of people with discrete smoking patterns, and we could examine several potential predictors for belonging to each trajectory. Furthermore, we were able to follow changes in smoking intensity during retirement transition, a question that has received little attention up to date. Our results were based on a relatively homogeneous group of workers, who retired based on their age and not because of health reasons. Thus, an illness leading to early retirement and simultaneously to quitting smoking is an unlikely source of bias in our study. Lack of biological measures to validate self-reported smoking is a weakness of this study. However, self-report is a reasonably valid method to measure smoking behaviours among Finns [31], thus we expect no large misclassification of tobacco use, especially among the baseline current smokers. However, the study population consisted mainly of participants with European origin in a Scandinavian welfare state with strict antismoking policies, which may limit the generalizability to 
other populations and countries. Furthermore, comparing results on quitting smoking between studies is challenging because countries are in different phases of the cigarette epidemic.

Some longitudinal studies have reported decreasing smoking prevalence during retirement transition $[5,13]$ and it is well documented that smoking prevalence decreases with increasing age [32]. Our findings suggest that transition to statutory retirement has an independent effect on quitting smoking and it is not solely explained by age-related changes. However, it should be noted that effects of retirement may not take place at the very time of retirement, but part of the quitting we observed before or after retirement may have been due to retirement transition as well. Smoking cessation, even later in life, is beneficial for health [33]. We found a subgroup of smokers who reduced their smoking intensity during retirement transition. This reduction in smoking intensity, which seems to persist for a long period of time, is in agreement with two previous Japanese studies demonstrating reduction in smoking intensity during a shorter, two [14] to four year [11] follow-up period. In addition, we observed two subgroups of people who sustained their smoking intensity, either at high or low level, throughout the retirement transition. In contrast to the findings from one study in which retirement was associated with an increase in the number of cigarettes smoked [10], we did not find a subgroup for increasing smoking intensity. This is an important observation as there are less smoking-related restrictions, such as workplace bans, after retirement.

Living outside the inner urban area was the only factor that predicted a decrease in smoking prevalence, as compared to sustained smoking. There may be other factors, not measured in our study, that affect smoking behaviours around retirement such as work-related habits and changes in social relationships. Nevertheless, home neighbourhood as a predictor of decreasing smoking warrants more research on the area-level factors that might support quitting smoking during 
retirement transition. People in socioeconomically disadvantaged neighbourhoods smoke more than their peers in affluent neighbourhoods, independently of individual level socioeconomic status [25]. For many individuals, retirement means spending more time in their neighbourhoods. It is plausible that the neighbourhood might have even larger role in health behaviours after than before retirement. People living in the urban as opposed to rural areas are also more likely to smoke [34], and quitting is affected by the availability of tobacco products [35]. Given that the availability of cigarettes is higher in urban areas, living outside urban area may be predictive of healthier smoking behaviours. However, other studies should be conducted to find out if the rural environment is supportive of quitting smoking in countries with different urban structure.

In conclusion, retirement transition is a life stage where smokers have almost two times higher odds of quitting smoking than immediately before or after retirement. Compared to sustained smoking, quitting smoking was predicted by living outside the inner urban areas. Further studies should explore the reasons for quitting or decreasing smoking during retirement transition, and formulate interventions taking advantage of retirement being a window of opportunity for quitting smoking. In addition, further research should examine neighbourhood-level factors that might support reducing or quitting smoking among retirees. 


\section{Conflict of interest}

The authors declare no conflict of interest.

\section{Funding}

This work was supported by Academy of Finland (grant numbers 286294 and 294154 to SS and 311492 to MK), the Finnish Ministry of Education and Culture (to SS); the Juho Vainio Foundation (to SS); Finnish Work Environment Fund; and NordForsk, the Nordic Programme for Health and Welfare (grant number 75021 to MK). 
Table 1. Characteristics of the participants before retirement ( $\left.\mathrm{w}_{-1}\right)$.

\begin{tabular}{|c|c|c|c|c|c|c|}
\hline & \multicolumn{3}{|c|}{$\begin{array}{l}\text { Smoking status analysis } \\
(\mathrm{n}=1,432)\end{array}$} & \multicolumn{3}{|c|}{$\begin{array}{l}\text { Smoking intensity analysis } \\
(\mathrm{n}=489)\end{array}$} \\
\hline & $\mathrm{n}$ & $\%$ & $\mathrm{n}$ missing & $\mathrm{n}$ & $\%$ & $\mathrm{n}$ missing \\
\hline Male & 506 & 35 & 0 & 154 & 31 & 0 \\
\hline Age at retirement & & & 0 & & & 0 \\
\hline$<60$ & 207 & 14 & & 67 & 14 & \\
\hline $60-64$ & 1002 & 70 & & 344 & 70 & \\
\hline$>64$ & 223 & 16 & & 78 & 16 & \\
\hline Marital status & & & 19 & & & 8 \\
\hline Married/cohabiting & 1031 & 72 & & 327 & 67 & \\
\hline Divorced/widowed & 312 & 22 & & 131 & 27 & \\
\hline Single & 70 & 5 & & 23 & 5 & \\
\hline Occupational status & & & 6 & & & 0 \\
\hline Low & 522 & 36 & & 203 & 42 & \\
\hline Intermediate & 385 & 27 & & 128 & 26 & \\
\hline High & 519 & 36 & & 158 & 32 & \\
\hline Education & & & 0 & & & 0 \\
\hline Low & 251 & 18 & & 100 & 20 & \\
\hline Intermediate & 428 & 30 & & 157 & 32 & \\
\hline High & 753 & 53 & & 232 & 47 & \\
\hline Poor self-rated health & 564 & 40 & 9 & 199 & 41 & 5 \\
\hline$\geq 1$ chronic diseases & 189 & 13 & 0 & 52 & 11 & 0 \\
\hline Depression & 190 & 13 & 139 & 75 & 15 & 47 \\
\hline Heavy alcohol consumption & 265 & 19 & 4 & 100 & 20 & 2 \\
\hline Low physical activity & 642 & 45 & 9 & 249 & 51 & 4 \\
\hline Overweight or obese & 829 & 58 & 31 & 261 & 54 & 10 \\
\hline Living in inner urban area & 681 & 48 & 10 & 246 & 50 & 5 \\
\hline $\begin{array}{l}\text { Neighbourhood disadvantage } \\
\text { above national mean }\end{array}$ & 497 & 35 & 64 & 193 & 39 & 26 \\
\hline Job strain & 323 & 23 & 28 & 118 & 24 & 8 \\
\hline
\end{tabular}


Table 2. Pseudo-trials on the effect of retirement on change in smoking. Odds ratios (OR) and their 95\% confidence intervals (CI) for change in smoking status during retirement transition ("treatment" group) compared to that in no retirement transition ("control" group).

\begin{tabular}{|c|c|c|c|c|c|c|c|}
\hline \multirow[b]{3}{*}{$\begin{array}{l}\text { No retirement } \\
\text { transition }{ }^{1} \\
\text { "control" }\end{array}$} & \multicolumn{7}{|c|}{ Outcome: Quitting smoking } \\
\hline & $\begin{array}{l}\text { Number of } \\
\text { participants }\end{array}$ & $\begin{array}{l}\text { Number of } \\
\text { paired } \\
\text { observations }\end{array}$ & $\begin{array}{l}\text { Mean number } \\
\text { of paired } \\
\text { observations } \\
\text { /person }\end{array}$ & Quitted & Did not quit & $\begin{array}{l}\text { OR for } \\
\text { quitting }\end{array}$ & $95 \% \mathrm{CI}$ \\
\hline & 465 & 695 & 1.5 & $138(20 \%)$ & $557(80 \%)$ & 1 (ref) & \\
\hline \multirow{3}{*}{$\begin{array}{l}\text { Retirement transition }{ }^{2} \\
\text { "treatment" }\end{array}$} & 497 & 497 & 1 & $145(29 \%)$ & $352(71 \%)$ & 1.65 & 1.26 to 2.17 \\
\hline & \multicolumn{7}{|c|}{ Outcome: Smoking relapse } \\
\hline & $\begin{array}{l}\text { Number of } \\
\text { participants }\end{array}$ & $\begin{array}{l}\text { Number of } \\
\text { paired } \\
\text { observations }\end{array}$ & $\begin{array}{l}\text { Mean number } \\
\text { of paired } \\
\text { observations } \\
\text { /person }\end{array}$ & Relapsed & $\begin{array}{l}\text { Did not } \\
\text { relapse }\end{array}$ & $\begin{array}{l}\text { OR for } \\
\text { relapsing }\end{array}$ & $95 \% \mathrm{CI}$ \\
\hline $\begin{array}{l}\text { No retirement } \\
\text { transition } 1 \\
\text { "control" }\end{array}$ & 914 & 1527 & 1.7 & $42(3 \%)$ & $1485(97 \%)$ & 1 (ref) & \\
\hline $\begin{array}{l}\text { Retirement transition }{ }^{2} \\
\text { "treatment" }\end{array}$ & 935 & 935 & 1 & $28(3 \%)$ & $907(97 \%)$ & 1.08 & 0.70 to 1.67 \\
\hline
\end{tabular}


Table 3. Pre-retirement ( $\left.\mathrm{w}_{-1}\right)$ predictors, adjusted for sex and year of birth, for belonging to the trajectory of sustained non-smoking or decreasing smoking compared to sustained smoking $(\mathrm{n}=1,432)$

\begin{tabular}{|c|c|c|c|c|c|c|}
\hline \multirow{3}{*}{$\begin{array}{l}\text { Variable } \\
\text { Female vs. male }\end{array}$} & \multicolumn{3}{|c|}{$\begin{array}{l}\text { Sustained non-smoking vs. } \\
\text { sustained smoking }\end{array}$} & \multicolumn{3}{|c|}{$\begin{array}{l}\text { Decreasing smoking vs. } \\
\text { sustained smoking }\end{array}$} \\
\hline & \multirow{2}{*}{$\frac{\text { OR }}{0.75}$} & \multicolumn{2}{|c|}{$95 \% \mathrm{CI}$} & \multirow{2}{*}{$\frac{\text { OR }}{0.69}$} & \multicolumn{2}{|c|}{$95 \% \mathrm{CI}$} \\
\hline & & 0.55 & 1.02 & & 0.44 & 1.10 \\
\hline \multicolumn{7}{|l|}{ Age at retirement } \\
\hline$>64$ vs. $<60$ & 0.87 & 0.51 & 1.48 & 1.54 & 0.66 & 3.58 \\
\hline $60-64$ vs. $<60$ & 0.96 & 0.65 & 1.44 & 1.11 & 0.57 & 2.15 \\
\hline \multicolumn{7}{|l|}{ Marital status } \\
\hline Married/cohabiting vs. single & 0.98 & 0.51 & 1.92 & 0.85 & 0.30 & 2.39 \\
\hline Divorced/widowed vs. single & 0.62 & 0.31 & 1.25 & 0.80 & 0.27 & 2.35 \\
\hline \multicolumn{7}{|l|}{ Occupational status } \\
\hline High vs. low & 1.64 & 1.17 & 2.29 & 1.47 & 0.90 & 2.41 \\
\hline Intermediate vs. low & 1.23 & 0.88 & 1.71 & 0.75 & 0.38 & 1.47 \\
\hline \multicolumn{7}{|l|}{ Education } \\
\hline High vs. low & 1.87 & 1.29 & 2.71 & 1.63 & 0.89 & 2.98 \\
\hline Intermediate vs. low & 1.30 & 0.87 & 1.92 & 1.27 & 0.67 & 2.41 \\
\hline Good vs. poor self-rated health & 1.16 & 0.87 & 1.54 & 0.82 & 0.53 & 1.26 \\
\hline No vs. $\geq 1$ chronic diseases & 0.78 & 0.51 & 1.20 & 0.94 & 0.46 & 1.93 \\
\hline No depression vs. has depression & 1.23 & 0.89 & 1.83 & 1.17 & 0.61 & 2.24 \\
\hline $\begin{array}{l}\text { Low or moderate vs. heavy } \\
\text { alcohol consumption }\end{array}$ & 1.39 & 0.99 & 1.95 & 1.46 & 0.80 & 2.67 \\
\hline $\begin{array}{l}\text { Moderate-to-high vs. low } \\
\text { physical activity }\end{array}$ & 1.49 & 1.12 & 1.98 & 0.95 & 0.60 & 1.51 \\
\hline $\begin{array}{l}\text { Normal weight vs. } \\
\text { overweight/obese }\end{array}$ & 0.69 & 0.51 & 0.92 & 0.72 & 0.46 & 1.14 \\
\hline $\begin{array}{l}\text { Living outside vs. inside inner } \\
\text { urban area }\end{array}$ & 1.50 & 1.13 & 1.99 & 1.78 & 1.15 & 2.76 \\
\hline $\begin{array}{l}\text { Living in advantaged vs. } \\
\text { disadvantaged neighbourhood }\end{array}$ & 1.53 & 1.14 & 2.06 & 1.27 & 0.80 & 2.03 \\
\hline No job strain vs. has job strain & 1.07 & 0.76 & 1.50 & 0.83 & 0.49 & 1.40 \\
\hline
\end{tabular}

Note: Boldface indicates statistical significance $(p<0.05)$.

OR, odds ratio 
Table 4. Pre-retirement ( $\left.\mathrm{w}_{-1}\right)$ predictors, adjusted for sex and year of birth, for belonging to the trajectory of sustained low intensity smoking or decreasing high intensity smoking compared to sustained high intensity smoking $(\mathrm{n}=489)$

\begin{tabular}{|c|c|c|c|c|c|c|}
\hline \multirow{3}{*}{$\begin{array}{l}\text { Variable } \\
\text { Female vs. male }\end{array}$} & \multicolumn{3}{|c|}{$\begin{array}{l}\text { Sustained low intensity } \\
\text { smoking vs. Sustained high } \\
\text { intensity smoking }\end{array}$} & \multicolumn{3}{|c|}{$\begin{array}{l}\text { Decreasing high intensity } \\
\text { smoking vs. Sustained high } \\
\text { intensity smoking }\end{array}$} \\
\hline & \multirow{2}{*}{$\begin{array}{l}\text { OR } \\
\mathbf{3 . 8 4}\end{array}$} & \multicolumn{2}{|c|}{$95 \% \mathrm{CI}$} & \multirow{2}{*}{$\begin{array}{l}\text { OR } \\
0.91\end{array}$} & \multicolumn{2}{|c|}{$95 \% \mathrm{CI}$} \\
\hline & & 2.02 & 7.32 & & 0.46 & 1.81 \\
\hline \multicolumn{7}{|l|}{ Age at retirement } \\
\hline$>64$ vs. $<60$ & 4.14 & 1.39 & 12.27 & 2.14 & 0.60 & 7.70 \\
\hline $60-64$ vs. $<60$ & 1.81 & 0.82 & 3.98 & 1.04 & 0.45 & 2.38 \\
\hline \multicolumn{7}{|l|}{ Marital status } \\
\hline Married/cohabiting vs. single & 0.97 & 0.18 & 5.20 & 0.27 & 0.05 & 1.54 \\
\hline Divorced/widowed vs. single & 0.57 & 0.10 & 3.13 & 0.34 & 0.06 & 2.01 \\
\hline \multicolumn{7}{|l|}{ Occupational status } \\
\hline High vs. low & 1.28 & 0.70 & 2.32 & 0.99 & 0.48 & 2.06 \\
\hline Intermediate vs. low & 0.92 & 0.49 & 1.74 & 0.86 & 0.38 & 1.92 \\
\hline \multicolumn{7}{|l|}{ Education } \\
\hline High vs. low & 1.45 & 0.75 & 2.82 & 0.90 & 0.39 & 2.04 \\
\hline Intermediate vs. low & 1.64 & 0.78 & 3.44 & 1.25 & 0.49 & 3.18 \\
\hline Good vs. poor self-rated health & 2.09 & 1.25 & 3.49 & 0.68 & 0.35 & 1.32 \\
\hline No vs. $\geq 1$ chronic diseases & 1.53 & 0.67 & 3.47 & 1.54 & 0.54 & 4.35 \\
\hline No depression vs. has depression & 1.29 & 0.65 & 2.58 & 1.13 & 0.44 & 2.92 \\
\hline $\begin{array}{l}\text { Low or moderate vs. heavy } \\
\text { alcohol consumption }\end{array}$ & 1.43 & 0.78 & 2.61 & 1.69 & 0.79 & 3.64 \\
\hline $\begin{array}{l}\text { Moderate-to-high vs. low } \\
\text { physical activity }\end{array}$ & 1.73 & 1.04 & 2.87 & 1.07 & 0.56 & 2.04 \\
\hline $\begin{array}{l}\text { Normal weight vs. } \\
\text { overweight/obese }\end{array}$ & 1.69 & $\mathbf{1 . 0 3}$ & 2.76 & 0.91 & 0.49 & 1.69 \\
\hline $\begin{array}{l}\text { Living outside vs. inside inner } \\
\text { urban area }\end{array}$ & 1.20 & 0.72 & 2.01 & 1.15 & 0.60 & 2.21 \\
\hline $\begin{array}{l}\text { Living in advantaged vs. } \\
\text { disadvantaged neighbourhood }\end{array}$ & 2.13 & 1.17 & 3.89 & 0.81 & 0.43 & 1.50 \\
\hline No job strain vs. has job strain & 1.40 & 0.76 & 2.58 & 0.93 & 0.47 & 1.86 \\
\hline
\end{tabular}

Note: Boldface indicates statistical significance $(p<0.05)$.

OR, odds ratio 


\section{References}

1. Kim JE and Moen P. Retirement Transitions, Gender, and Psychological Well-Being A Life-Course, Ecological Model. J Gerontol B Psychol Sci Soc Sc 2002;57:P212-P222.

2. Stenholm S, Pulakka A, Kawachi I, et al. Changes in physical activity during transition to retirement: a cohort study. Int J Behav Nutr Phys Act 2016;13:51.

3. Halonen JI, Stenholm S, Pulakka A, et al. Trajectories of risky drinking around the time of statutory retirement: a longitudinal latent class analysis. Addiction 2017;112:1163-1170.

4. Lang IA, Rice NE, Wallace RB, et al. Smoking cessation and transition into retirement: analyses from the English Longitudinal Study of Ageing. Age Ageing 2007;36:638-643.

5. Tamers SL, Okechukwu C, Marino M, et al. Effect of stressful life events on changes in smoking among the French: longitudinal findings from GAZEL. Eur J Public Health 2015;25:711-715.

6. Skogen JC, Øverland S and Knudsen AK. Health-related behaviour in relation to transition into age retirement: an observational study based on HUNT3. JRSM Open 2016;7:1-8.

7. Ding D, Grunseit AC, Chau JY, et al. Retirement - a Transition to a healthier lifestyle? Evidence from a large Australian study. Am J Prev Med 2016;51:170-178.

8. van Solinge $\mathrm{H}$ and Henkens K. Adjustment to and satisfaction with retirement: two of a kind?. Psychol Aging 2008;23:422-434.

9. Pinquart $M$ and Schindler I. Changes of life satisfaction in the transition to retirement: a latent-class approach. Psychol Aging 2007;22:442-455.

10. Ayyagari P. The impact of retirement on smoking behavior. East Econ J 2016;42:270-287.

11. Zhao M, Noguchi H and Konishi Y. Retiring for better health? Evidence from health investment behaviors in Japan. Report no. 2011-005, March 2012.

12. Kesavayuth D, Rosenman R and Zikos V. Retirement and health behavior. Report no. WP 2016-3.

13. Oshio T and Kan M. The dynamic impact of retirement on health: evidence from a nationwide tenyear panel survey in Japan. Prev Med 2017;100:287-293.

14. Motegi H, Nishimura Y and Terada K. Does retirement change lifestyle habits?. The Japanese Economic Review 2016;67:169-191.

15. Halonen JI, Kivimäki M, Kouvonen A, et al. Proximity to a tobacco store and smoking cessation: a cohort study. Tob Control 2014;23:146-151. 
16. Classification of occupations 2001 [Internet]. Statistics Finland.

http://www.stat.fi/meta/luokitukset/ammatti/001-2001/index_en.html, accessed 9 May 2018).

17. Education [Internet]. Statistics Finland. http://www.stat.fi/til/kou_en.html (2018, accessed 14 March 2018).

18. Current Care Guidelines: Alkoholiongelmaisen hoito [Treatment of alcohol abuse] [Internet]. Finnish Medical Society Duodecim.

http://www.kaypahoito.fi/web/english/guidelineabstracts/guideline?id=ccs00005 (2015, accessed 27 June 2017).

19. Ainsworth BE, Haskell WL, Herrmann SD, et al. 2011 Compendium of physical activities: a second update of codes and MET values. Med Sci Sports Exerc 2011;43:1575-1581.

20. U.S. Department of Health and Human Services. Physical activity guidelines advisory committee report, 2008.

21. WHO Consultation on Obesity. Obesity: preventing and managing the global epidemic: report of a WHO consultation. Report no. 894.

22. Karasek R, Brisson C, Kawakami N, et al. The Job Content Questionnaire (JCQ): An instrument for internationally comparative assessments of psychosocial job characteristics. J Occup Health Psychol 1998;3:322-355.

23. Heikkilä K, Nyberg ST, Fransson EI, et al. Job strain and tobacco smoking: An individualparticipant data meta-analysis of 166130 adults in 15 European studies. PLoS ONE 2012;7:e35463.

24. Grid database [Internet]. Statistics Finland.

http://www.tilastokeskus.fi/tup/ruututietokanta/index en.html, accessed 11 June 2018).

25. Halonen JI, Pulakka A, Stenholm S, et al. Effect of a change in neighbourhood disadvantage on smoking behaviors in adults: a longitudinal within-individual study. Epidemiology 2016;27:803-809.

26. Urban-rural classification [Internet]. Finnish Environment Institute SYKE. http://www.ymparisto.fi/en-

US/Living environment and planning/Community structure/Information about the community stru cture/Urbanrural_classification (2018, accessed 7 Jun 2018).

27. Hernan MA, Alonso A, Logan R, et al. Observational studies analyzed like randomized experiments: an application to postmenopausal hormone therapy and coronary heart disease. Epidemiology 2008;19:766-779.

28. Clark AJ, Salo P, Lange T, et al. Onset of impaired sleep as a predictor of change in health-related behaviours; analysing observational data as a series of non-randomized pseudo-trials. Int J Epidemiol 2015;44:1027-1037. 
29. Lanza ST, Collins LM, Lemmon DR, et al. PROC LCA: A SAS procedure for latent class analysis. Struct Equ Modeling 2007;14:671-694.

30. Fitzpatrick KE, Gray R and Quigley MA. Women's longitudinal patterns of smoking during the pre-conception, pregnancy and postnatal period: Evidence from the UK Infant Feeding Survey. PLOS ONE 2016;11:e0153447.

31. Vartiainen E, Seppälä T, Lillsunde P, et al. Validation of self reported smoking by serum cotinine measurement in a community-based study. J Epidemiol Community Health 2002;56:167-170.

32. $\mathrm{Ng} \mathrm{M}$, Freeman MK, Fleming TD, et al. Smoking prevalence and cigarette consumption in 187 countries, 1980-2012. JAMA 2014;311:183-192.

33. Gellert C, Schöttker B and Brenner H. Smoking and all-cause mortality in older people: systematic review and meta-analysis. Arch Intern Med 2012;172:837-844.

34. Airaksinen J, Hakulinen C, Pulkki-Råback L, et al. Neighbourhood effects in health behaviours: a test of social causation with repeat-measurement longitudinal data. Eur J Public Health 2016;26:417421.

35. Pulakka A, Halonen JI, Kawachi I, et al. Association between distance from home to tobacco outlet and smoking cessation and relapse. JAMA Intern Med 2016;176:1512-1519. 
Figure 1. Trajectories of current smoking among Finnish Public Sector Study participants who were current or former smokers immediately before retirement (A) and smoking intensity among those who were current smokers immediately before retirement (B) over six study waves (four-year intervals). W-3 $\ldots \mathrm{W}_{+3}$ present the study waves in relation to statutory retirement. Confidence intervals are truncated if they include $0 \%$ or $100 \%$.
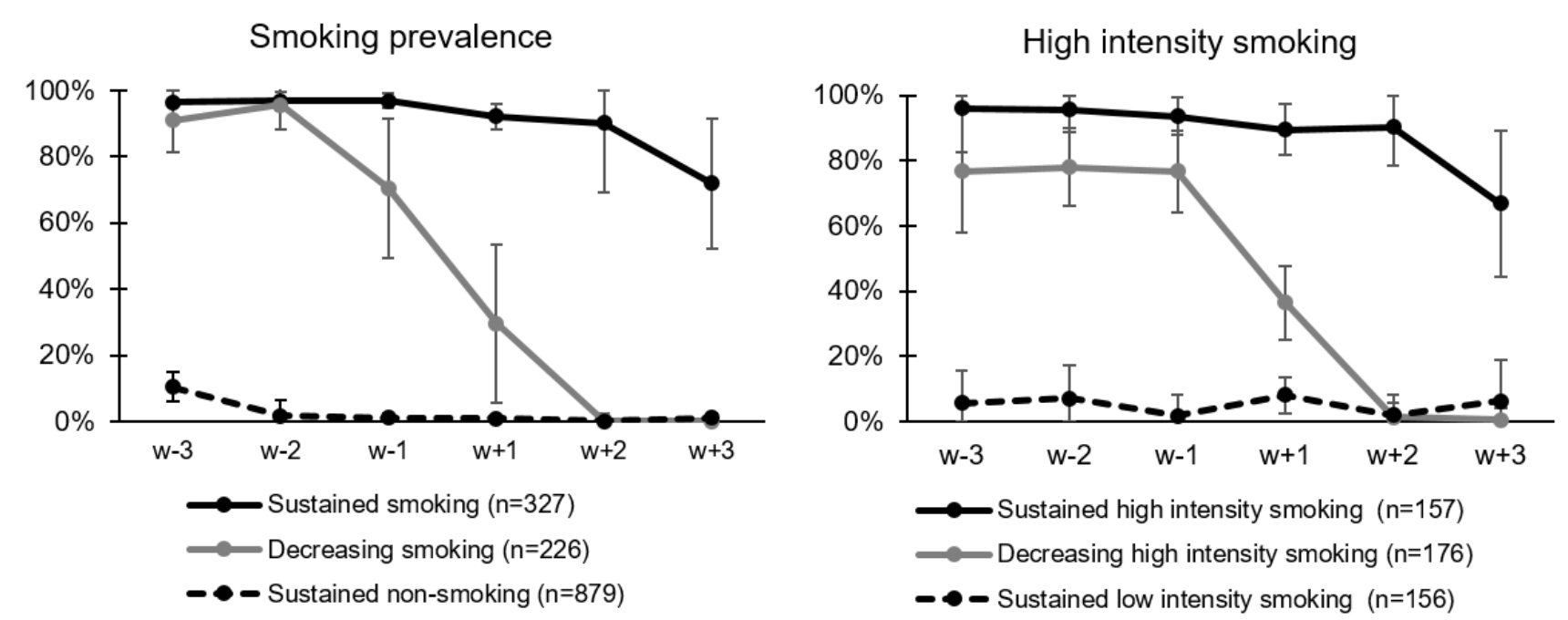

Supplemental Table S1. Model fit statistics of the latent class analysis (LCA) models with different one to five latent classes.

Supplemental Figure S1. Number of the Finnish Public Sector Study participants at each possible survey wave and illustration of the survey wave pairs included in the pseudo trial.

Supplemental Figure S2. Flow chart of the selection of the study sample 